\begin{tabular}{ccc}
\hline & $\begin{array}{c}\text { International Journal of Health Services, } \\
\text { Research and Policy } \\
\text { www.dergipark.org.tr/ijhsrp }\end{array}$ \\
$\begin{array}{c}\text { INTESEG } \\
\text { ENGINETIONAL } \\
\text { SCIENCE AND } \\
\text { EDUCATION GROUP }\end{array}$ & e-ISSN: 2602-3482 & IJHSRP \\
\hline
\end{tabular}

Research Article

\title{
EVALUATION OF RDW, MPV, PLATELET LABORATORY PARAMETERS IN PROSTATE CANCER PATIENTS ADMITTING TO EMERGENCY DEPARTMENT WITH HEMATURIA
}

\author{
Dilek Atik ${ }^{* 1}$ iD \\ ${ }^{1}$ Yozgat Bozok University, Department of Emergency Medicine, Yozgat, Turkey \\ * Corresponding author; dr.dilekgok82@ hotmail.com
}

\begin{abstract}
Prostate Cancer (PCA) is the most common among urological malignant tumors. Prostate cancer patients may be unable to urinate and may have hospital admissions with symptoms like erectile dysfunction or hematuria. Although hematuria is a highly common clinical manifestation in society, the frequency of it is not known in prostate cancer patients, which is one of the urological malignancies. The purpose of this study was to investigate the relation of RDW (distribution width of the red blood cells), MPV (mean platelet volüme), and Platelet Blood Parameters with hematuria in prostate cancer patients admitting to the emergency clinic with hematuria. The present study was conducted retrospectively by examining the hospital automation system and patient files of prostate cancer patients admitting with hematuria between 01.01.2018-01.01.2020 to Yozgat Bozok University Emergency Medical Clinic. A total of 60 patients with full files and that matched study criteria were included in the study. For the purpose of comparing blood parameters, 45 patients with prostate cancer, nonspecific complaints, and non-additional diseases were evaluated as the control group. MPV (mean platelet volume), RDW-CV (red blood cells distribution width) blood parameters of patients with prostate cancer hematuria were found to be significantly higher in the control group. The platelet value of the patient group was found to be significantly lower than the control group. However, the platelet blood parameter values were significantly lower in patients with major hematuria than in patients with minor hematuria $(<0.05)$. According to the results of the present study, we believe that all the three parameters $(R D W$, $M P V$, and Platelet levels), which can be measured in full blood count in the prostate cancer patient group, in particular, can guide clinicians that the finding of hematuria can develop, and will be beneficial in follow-up and treatment. However, unlike RDW and MPV laboratory parameters, we think the Platelet parameter is an important parameter in predicting the type of hematuria that can develop.
\end{abstract}

Keywords: Prostate Cancer, Hematuria, RDW, MPV, Platelet 


\section{Introduction}

Prostate Cancer (PCA) is the most common among urological malignant tumors. [1.2] However, it is the second cause after lung cancer in cancer-related deaths in the male gender [3]. Prostate cancer patients may be unable to urinate and may have hospital admissions with symptoms like erectile dysfunction or hematuria [4]. Hematuria is a rare finding in normal physiology that raises concerns in people [5]. It is also a clinical manifestation common in society and can reach up to $20 \%$ in terms of prevalence [6, 7]. Many factors, which include exercise, inflammation, structural deterioration, malignancy, and trauma can cause hematuria [8]. Although hematuria is a highly common clinical manifestation in society, the frequency of it is not known in prostate cancer patients, which is one of the urological malignancies [9].

Hematuria appears before us in two ways. Macroscopic hematuria can be seen in the patient's urine, which allows the patient to come to the physician more quickly [10]. More than 50\% of patients who have macroscopic hematuria have an important urogenital system disease [11]. Macroscopic hematuria is known as a high-risk symptom for prostate cancer [12]. Another form is microscopic hematuria [7, 13], defined as the presence of more than 3 red blood cells in each large magnification area in 2 of 3 microscopic examinations of urine analyses at 2-3-week intervals. Microscopic hematuria varies clinically. The appearance of at least 3 erythrocytes in a single urine sample in a high-risk patient group in terms of cancer requires general urological evaluation [13].

In the literature, it is reported that hematuria might stem from bleeding, petechial rash, nose bleeding, gastrointestinal bleeding, retinal bleeding, and brain bleeding may be because of platelet miscarriage [14]. The numerical change in platelet blood cells playing direct roles in clotting and inflammatory regulation can cause bleeding [15]. It was reported in a study in the literature that platelet increase was a predictor in hidden malignancies [16]. However, the Mean Platelet Volume (MPV), which is also part of this study, reflects the platelet size that is associated with platelet production and activation $[17,18]$. In a healthy population, there is an inverse relation between MPV and platelet count [13]. Some studies emphasize that the MPV and platelet values vary with the changes in blood parameters in patients with malignancies [19, 20].

Another parameter included in our study, the RDW (distribution width of the red blood cells) has a linear relation with recurrent or massive bleeding of the laboratory parameter [21, 22]. RDW is a variation coefficient of the red blood cell volume, which can be routinely tested in full blood count. It usually increases because of erythropoiesis deficiencies or accelerated red blood cell destruction [23]. The increase in the diameter variability of the erythrocytes causes increases in the erythrocyte distribution volume (RDW) [24]. It is reported in the literature that the RDW laboratory parameter increases especially in studies related to anemia, chronic renal failure, and heart failure [23, 25]. Some studies reported that RDW value is a predictor of mortality in coronary artery disease and cancer cases [26]. However, in the literature, it was also reported that the RDW parameter is an indicator of inflammation [27]. In a previous study, it was emphasized that the RDW Laboratory Parameter might be used in the evaluation of progression in prostate cancer patients [53].

The purpose of this study was to investigate the relation of RDW, MPV, and Platelet Blood Parameters with hematuria in prostate cancer patients admitting to the emergency clinic with hematuria. 


\section{Method}

\subsection{Study Design}

The present study was conducted retrospectively by examining the hospital automation system and patient files of prostate cancer patients admitting with hematuria between 01.01.2018-01.01.2020 to Yozgat Bozok University Emergency Medical Clinic. Patients who were over the age of 18 were included in the study. Approval was obtained from the Local Ethics Committee for the study. A total of 60 patients with full files and that matched study criteria were included in the study. For the purpose of comparing blood parameters, 45 patients with prostate cancer, nonspecific complaints, and nonadditional diseases were evaluated as the control group. The full blood count values were recorded for the PCA and hematology patients in the first 24 hours of hospital admissions analyzed from the venous blood kept at EDTA tubes and analyzed with Sysmex XN-1000, Japanese hematological analyzer. In the blood analysis, MPV, RDW, Platelet (Plt) blood parameters were recorded in files of each patient, and for the control group. Patients with hematuria and other diseases (i.e. renal failure, renal stone, urinary tract infection), because of prostate cancer, which could lead to similar clinical findings, patients with hematuria and patients with urea and creatinine values outside normal limits were excluded from the study.

Ethical statements: Before the commencement of the study, the approval of the necessary ethics committee was obtained from the Yozgat Bozok University Ethics Committee of Clinical Researches (Date: 11/12/2019 Number: 2019-11-280).

\subsection{Statistical analysis}

All statistical data were analyzed with SPSS 20.0 version program for Windows. Demographic examination of patients was made with descriptive statistic data. The Chi-Square test was used in the study if the data were qualitative. When the study data were evaluated, the numerical values were expressed as mean \pm standard deviation. The study that was conducted in the scope of clinical research used the Mann-Whitney U-test in statistical evaluations that depended on statistically parametric and statistical changes between two independent groups, the student $\boldsymbol{t}$-test, the nonparametric relationship variables, categorical (nominal or ordinal), the numerical independent group were used. Spearman Correlation Method was used in non-parametric data for the correlations between the study data. Laboratory parameters, which were significant in hematuria according to clinical results, were evaluated with ROC curve (Receiver-Operating Characteristics Curve). The level of significance was considered $\mathrm{p}<0.05$ in all comparisons.

\section{Results}

A total of $70.2 \%(n=42)$ of the total of 60 patients included in the study were minor hematuria patients $(\mathrm{MHH})$, and $29.8 \%(\mathrm{n}=18)$ were major hematuria patients. A total of 45 control groups (CG) were included in the study. The mean age of the patients with hematuria was $69.4 \pm 9.3$, and the mean age of the Control Group was 67.2 \pm 7.4. No statistically significant differences were detected in the intergroup age factor $(\mathrm{t}: 1.344 ; \mathrm{p}=0.182)$. Although $63.8 \%(\mathrm{n}=38 \%)$ were discharged as a result of the final clinical result of the patients, $36.2 \%(n=22)$ patients were hospitalized. The PSA value of the patient group was $10.9 \pm 8.6 \mathrm{ng} / \mathrm{ml}$. The PSA value of the control group was 11.6 \pm 7.8.(t:234, $\mathrm{p}=0.816)$. 
When the prostate patient group and control groups admitted with hematuria are evaluated, RDW$\mathrm{CV}$ blood parameter values are shown in Table 1. The RDW blood parameter was found to be significantly high in the control group as shown in Table $1(\mathrm{p}<0.05)$. When the relation between RDW$\mathrm{CV}$ laboratory parameter level and hematuria was evaluated, a weak and positive relationship was detected $(\mathrm{p}<0.05)$ (Table 2). RDW-CV blood parameter was not statistically significant in minor and major hematuria patients $(\mathrm{p}>0.05)$.

The MPV blood parameter values are summarized in Table 1. When the prostate patient groups admitting with hematuria were evaluated, the difference between the patient group and control groups in terms of MPV average was statistically significant $(p<0.05)$. When the relation between the MPV laboratory parameter and hematuria was evaluated, a weak and positive relation was found $(p<0.05)$ (Table 2). However, when MPV laboratory parameters were evaluated in major hematuria and minor hematuria, no statistically significant differences were detected $(\mathrm{p}>0.05)$.

Table 1. Analysis of Laboratory Parameters of Patient and Control Group

\begin{tabular}{|l|l|l|l|l|l|l|}
\hline $\begin{array}{l}\text { Laboratory } \\
\text { Parameters }\end{array}$ & $\begin{array}{c}\text { Control } \\
\text { groups(Mean } \pm \\
\text { Sd) }\end{array}$ & $\begin{array}{c}\text { Patient groups } \\
\text { (Mean } \pm \text { Sd) }\end{array}$ & $\begin{array}{c}\text { p } \\
\text { value }\end{array}$ & $\begin{array}{c}\text { Minor } \\
\text { hematuria } \\
\text { (Mean } \pm \text { Sd) }\end{array}$ & $\begin{array}{c}\text { Major } \\
\text { Hematuria(Me } \\
\text { an } \pm \text { Sd) }\end{array}$ & $\begin{array}{c}\text { p } \\
\text { value }\end{array}$ \\
\hline RDW-CV\% & $12.8 \pm 0.7$ & $13.6 \pm 1.5$ & $0.028^{*}$ & $13.2 \pm 1.7$ & $13.8 \pm 1.3$ & 0.379 \\
\hline MPV fl & $10.3 \pm 0.9$ & $11.2 \pm 1.3$ & $0.031^{*}$ & $10.9 \pm 0.9$ & $11 \pm 1.4$ & 0.815 \\
\hline $\begin{array}{l}\text { Platelet } \\
\mathbf{x ~ 1 0} / \mathbf{L}\end{array}$ & $209.08 \pm 61.5$ & $293 \pm 55.2$ & $0.000^{*}$ & $219.9 \pm 57.7$ & $175.4 \pm 32.7$ & $0.041^{*}$ \\
\hline
\end{tabular}

It was analyzed by Mann-Whitney $U$ test as statistical analysis. $*=p<0.05$ was considered significant. Sd: Standart deviation. RDW-CV: Distribution width of the red blood cells, MPV: m-Mean platelet volume.

Platelet blood parameter values are given in Table 1. According to this table, platelet values differed at statistically significant levels in patient groups and control groups $(p<0.05)$. When the relations between platelet levels and hematuria formation was evaluated, a high level of negative relation was detected $(\mathrm{p}<0.05)$ (Table 2). Also, Plt blood parameter values were significantly lower in patients with minor hematuria compared to major hematuria patients as shown in Table 1 ( $p<0.05)$. When the relation between hematuria and platelet and hematuria type was evaluated in patients with prostate cancer admitting with hematuria, a moderate and negative relation was found $(\mathrm{r}:-0.403, \mathrm{p} \leq 0.001)$.

Table 2. Correlation analysis of hematuria with RDW, MPV and Platelet laboratory parameters

\begin{tabular}{|l|l|c|}
\hline Laboratory Parameters & $\boldsymbol{r}$ & $\boldsymbol{P}$ \\
\hline RDW-CV & 0.302 & 0.026 \\
\hline MPV & 0.397 & 0.029 \\
\hline Platelet & -0.609 & 0.000 \\
\hline
\end{tabular}

Spearman Correlation Method was used. The level of significance was considered $\mathrm{p}<0.05$ in all comparisons. RDWCV: Distribution width of the red blood cells, MPV: m-Mean platelet volume. 
According to the results obtained in evaluating the development of hematuria of prostate cancer patients, EAA, cut-off, sensitivity, and specificity were analyzed with the ROC curve in differentiating the MPV, RDW-CV, and Platelet laboratory parameters to guide clinicians in patient monitoring. For the MPV laboratory parameter, EAA was $0.673 \%, 10.4 \mathrm{fl}, 65.2 \%$ and $65 \%$, respectively. For EAA, RDW-CV parameter, cut-off, sensitivity and specificity were $0.676 \%, 12.65 \%, 82.6 \%$ and $52 \%$, respectively (Figure 1). For platelet parameters, EAA, cut-off, sensitivity and specificity were $0.856 \%$, $272.0 \%, 87 \%$ and $68 \%$, respectively (Figure 2).

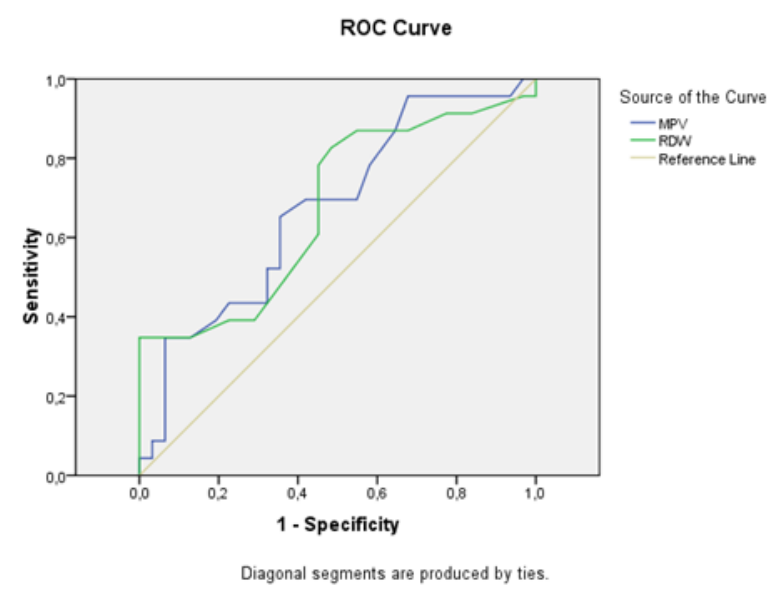

ROC Analysis of MPV, RDW laboratory parameter in patients with Hematuria; For the MPV laboratory parameter, EAA was $0.673 \%, 10.4$ fl, 65.2\%, and 65\%, respectively. For EAA, RDW-CV parameter, cut-off, sensitivity and specificity were $0.676 \%, 12.65 \%, 82.6 \%$ and $52 \%$.

Figure 1. ROC Analysis of MPV, RDW laboratory parameter in patients with Hematuria

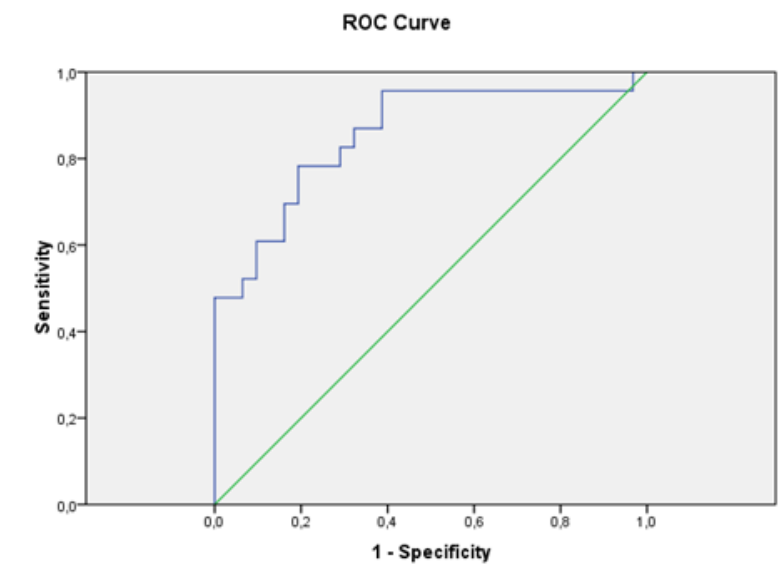

ROC Analysis of Platelet Laboratory parameter in patients with Hematuria AUC: 0.856, Cut-off point 272.0, lower limit: 0.749, upper limit: 0.962 .

Figure 2. ROC Analysis of Platelet Laboratory Parameter in Patients with Hematuria

According to the results obtained in the evaluation of the hematuria type of the prostate cancer patients, EAA, cut-off, sensitivity, and specificity were analyzed with the ROC curve in differentiating it for the clinician in patient follow-up with the significance of platelet laboratory parameter. For platelet 
parameters, EAA, cut-off, sensitivity and specificity were $0.752 \%, 218.0,53 \%$ and $88 \%$, respectively (Figure 3).

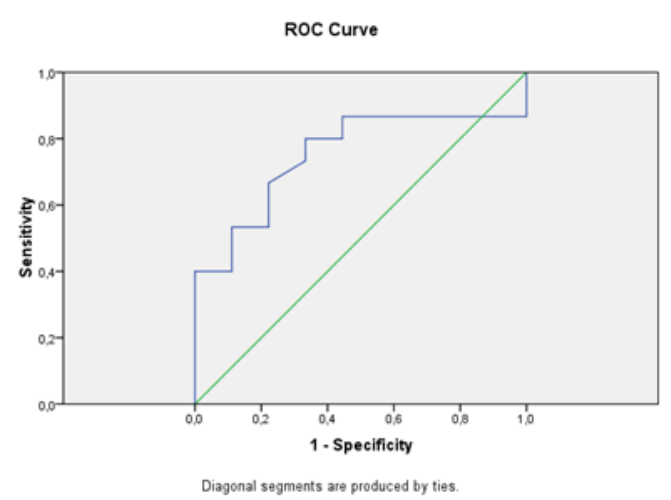

ROC Analysis of Platelet Laboratory parameter in hematuria type of patients with prostate cancer, For platelet parameters, EAA, cut-off, sensitivity, and specificity were $0.752 \%, 218.0,53 \%$, and $88 \%$.

Figure 3. ROC Analysis of Platelet Laboratory parameter in hematuria type of patients with prostate cancer

\section{Discussion}

Prostate Cancer is one of the most important health problems that affect the male gender. Hematuria is one of the acute symptoms faced by patients in urological malignity (28). The development of hematuria is a finding to be considered especially in prostate cancer patients (29). In $60 \%$ of the patients with major hematuria, prostate cancer exists in the etiology (30).

In the present study, we evaluated the effects of the difference in the Mean Platelet Volume (MPV), RDW-CV, and platelet values in the development of hematuria in prostate cancer patients admitting with hematuria. When literature was reviewed, studies on the effects of blood parameters in hematuria patients was limited. Hematuria develops because of many causes like kidney stone, urinary system infections in prostate cancer patients (9). According to the results of our study, RDW-CV blood parameter and MPV values were high when compared to the control group, and platelet values were low compared to the control group in prostate patients who developed hematuria. We also observed that platelet values affected major and minor hematuria.

The systemic inflammatory response is affected by tumor cells in the body. During the inflammatory process, many mediator platelets are activated and released [31, 32]. Platelets are observed in many cancer types $[33,34]$. Studies in the literature report that platelets especially in cancer patients affect survival $[35,36]$. In addition to the effects on inflammation and cancer, platelets are at the forefront in diseases characterized by bleeding. In the literature, low platelet levels are emphasized in some studies related to bleeding like uterine bleeding, GIS bleeding [37, 38, 39, 40]. According to the results of this study, low platelet levels were found in the group of patients with major hematuria. In their study conducted with patients with ITP, Piel-Julian et al. reported that the number of platelets affected macroscopic hematuria [41]. According to the results of our study, we believe that low platelet levels may be a predictive parameter in the formation of hematuria, which is supported by previous studies. However, the variability in the number of platelets can also affect major or minor hematuria. 
Mean Platelet Volume (MPV) is another parameter evaluated in full blood count showing the function and activation of MPV platelets from platelet parameters [42]. It was reported that MPV laboratory parameter has an inflammation parameter in some studies [43, 44]. In a study in the literature, hematuria and MPV parameters were associated with urinary system diseases [45]. Similarly, MPV value was significantly high in hematuria patients than in the control group in our study. In some studies, it was reported that the MPV value was effective in evaluating the clinic of patients in some patients with GIS bleeding [39, 46]. Unlike our study, in another study conducted on menstrual bleeding, which has a different bleeding focus, the MPV value was found to be lower than the controls [47]. We believe that this difference is because of the bleeding focus and mechanisms.

It was found that the RDW-CV parameters were high in the patient group when compared to the control group. In a study conducted with cancer patients, RDW value was found to be higher than the healthy control group. It was stated that there are different RDW values, especially in cancer types, and according to the localization [48]. The RDW blood parameter has a strong relation with inflammatory factors like C-reactive protein, erythrocyte sedimentation rate, and similar inflammatory factors. It was reported in the literature that the RDW was also an effective indicator in determining mortality $[49,50$, 51]. In a study conducted in the literature, the prognostic value of RDW-CV was reported especially in prostate cancer patients [52]. The fact that the patient group of our study had prostate cancer explains the elevated RDW levels. We believe that elevation of the RDW parameter in prostate cancer patients with hematuria compared to PCA patients who do not develop hematuria can predict the development of hematuria, which is a clinical characteristic in prostate cancer patients.

In the patient group evaluated in the scope of the study, it was found that the RDW laboratory parameter did not affect the hematuria type. However, we believe that there is no parameter that can be used to predict the type of hematuria.

The study had several limitations the first of which is was a relatively small sampling size and the second of which was the single-centered design of the study.

\section{Conclusion and Recommendations}

In conclusion, hematuria can develop in many diseases besides normal human physiology. According to the results of the present study, we believe that all the three parameters (RDW, MPV, and Platelet levels), which can be measured in full blood count in the prostate cancer patient group, in particular, can guide clinicians that the finding of hematuria can develop, and will be beneficial in follow-up and treatment. However, unlike RDW and MPV laboratory parameters, we think the Platelet parameter is an important parameter in predicting the type of hematuria that can develop.

Ethical statements: Before the commencement of the study, the approval of the necessary ethics committee was obtained from the Yozgat Bozok University Ethics Committee of Clinical Researches (Date: 11/12/2019 Number: 2019-11-280). The study was conducted in line with the principles of the Helsinki Declaration.

The compliance to Research and Publication Ethics: This work was carried out by obeying research and ethics rules. 
Conflict of Interest Statement: The authors reported that there was no conflict of interest.

\section{References}

[1] Townsend, C., Beauchamp, R.D., Evers, B.M., et al. (eds) Thomas Gillispie Smith MC III. Urologic surgery In: Sabiston textbook of surgery: the biological basis of modern surgical practice. 20th ed. Elsevier, New York, ,pp. 2100-2102, 2017.

[2] Narayan, V.M., Konety, B.R., Warlick, C., "Novel biomarkers for prostate cancer: an evidencebased review for use in clinical practice”, Int J Urol ,24(5), 352-360, 2017.

[3] Siegel, R.L., Miller, K.D., Jemal, A., “Cancer Istatistics” A Cancer J Clin, 65,5-29,2015.

[4] Nice Guideline, "Suspected cancer: recognition and referral", https://www.nice.org.uk/guidance/ng12, 1-95, 2015

[5] Hsieh, Y.P., Chang, C.C., Kor, C., Yang, Y., Wen, Y.K., Chiu, P.F., "The Predictive Role of Red Cell Distribution Width in Mortality among Chronic Kidney Disease Patients", PLoS One.,11(12), e0162025, 2016.

[6] Khadra, M.H., Pickard, R.S., Charlton, M., et al. "A prospective analysis of 1,930 patients with hematuria to evaluate current diagnostic practice”, J Urol, 163(2), 524-527,2000.

[7] Mariani, A.J., Mariani, M.C., Macchioni, C., "The significance of adult hematuria: 1,000 hematuria evaluations including a riskbenefit and cost-effectiveness analysis " $J$ Urol., 141, 350355,1989 .

[8] Sun, Y., Zhang, Y., Zhu, Y., Zhang, A., Huang, S., Yin, X., Ding, G., Liu, M., Jia, Z., "Inhibition of mitochondrial complex-1 restores the downregulation of aquaporins in obstructive nephropathy", Am J Physiol Renal Physiol, 1, 311(4),777-786, 2016.

[9] Gofrit, O.N., Katz, R., Amos, S. A., Yutkin, V., Galina, P., G., Zorn, K.C., Duvdevani, M., Landau, E.H., Pode, D., "Gross Hematuria in Patients with Prostate Cancer: Etiology and Management”, ISRN Surgery, 1-4,2013.

[10] Hageman, N., Aronsen, T., Tiselius, H.G., "A simple device (Hemostick) fort he standardized description of macroscopic hematuria: our initial experience", Scand J Urol Nephrol,40, 149,2006 .

[11] Glenn, S., Gerber, M.D., Charles, B., Brendler, M.D., "Evaluation of the urologic patient: History, physical examination, and urinalysis. Campbell-Walsh Urology", Ninth Edition. Philadelphia, pp. 81-110,2007.

[12] Gan, J.H., Harris, A.C., Green, J.S.A., "Quantifying the risk of malignancy in patients with visible haematuria presenting to the emergency department", J Clin Urol, 8(2),132-138,2015.

[13] Grossfeld, G.D., Litwin, M.S., Wolf, J.S., et al. "Evaluation of asymptomatic microscopic hematuria in adults: the American Urological Association best practice policy-part I: definition, detection, prevalence, and etiology" ,Urology, 57(4), 599-603,2001. 
[14] Greenberg, E.M., Kaled, E.S., “Thrombocytopenia”, Crit Care Nurs Clin North Am, 25(4),427$434,2013$.

[15] Hui, P., Cook, D.J., Lim, W., Fraser. G.A., Arnold, D.M., "The frequency and clinical significance of thrombocytopenia complicating critical illness: a systematic review",Chest, 139(2),271-278,2011.

[16] Bailey, S.E., Ukoumunne, O.C., Shephard, E., Hamilton, W., "How useful is thrombocytosis in predicting an underlying cancer in primary care? a systematic review", Family Practice, 34(1),4$10,2017$.

[17] Li, J.Y., Li, Y., Jiang, Z., Wang, R.T., Wang, X.S., "Elevated mean platelet volume is associated with the presence of colon cancer", Asian Pac J Cancer Prev, 15, 10501-10504,2014.

[18] Elsayed, A.M., Mohamed, G.A., "Mean platelet volume and mean platelet volume/platelet count ratio as a risk stratification tool in the assessment of the severity of acute ischemic stroke", Alexandria J Med., 53:67-70.2017.

[19] Cho, S.Y., Yang, J.J., You, E., Kim, B.H., Shim, J., Lee, H.J., et al., "Mean platelet volume/platelet count ratio in hepatocellular carcinoma", Platelets, 24,375-377,2013.

[20] Omar, M., Tanriverdi, O., Cokmert, S., Oktay, E., Yersal, O., Pilanc1, K.N., et al., "Role of increased mean platelet volume (MPV) and decreased MPV/platelet count ratio as poor prognostic factors in lung cancer", Clin Respir J., 12, 922-929,2018.

[21] Fatemi, O., Torguson, R., Chen, F., Ahmad, S., Badr, S., Satler, L.F., Pichard, A.D., Kleiman, N.S., Waksman, R., "Red cell distribution width as a bleeding predictor after percutaneous coronary intervention”, Am Heart J.,166(1),104-9,2013.

[22] Paulus, E.M., Weinberg, J.A., Magnotti, L.J., Sharpe, J.P., Schroeppel, T.J., Fabian, T.C., Croce, M.A.,"Admission red cell distribution width: a novel predictor of massive transfusion after injury", Am Surg, 80(7), 685-9,2014.

[23] Lu, Y.A., Fan, P.C., Lee, C.C., Wu, V.C.C., Tian, Y,.C., Yang, C.W., Chen, Y.C., Chang, C.H., "Red cell distribution width associated with adverse cardiovascular outcomes in patients with chronic kidney disease", BMC Nephrol,18, 361-371,2017.

[24] Fukuta, H., Ohte, N., Mukai, S., Saeki, T., Asada, K., Wakami, K., et al.” Elevated Plasma Levels of B-Type Natriuretic Peptide but not C- Reactive Protein are Associated with Higher Red Cell Distribution Width in Patients with Coronary Artery Disease”, Int Heart J.,50,301-312, 2009.

[25] Vaya, A., Hernandez, J.L., Zorio, E., et al.,” Association between red blood cell distribution width and the risk of future cardiovascular events", Clin Hemorheol Micro, 50, 221 - 225,2012.

[26] Patel, K.V., Semba, R.D., Ferucci, L., Newman, A.B., Wallece, R.B., Bandinelli, S., et al., "Red Cell Distribution Width and Mortality in Older Adults: A-Meta Analysis" , J Gerontol A Biol Sci Med Sci,65, 258-265,2010.

[27] Öztürk, Z.A., Ünal, A., Yiğiter, R., Yesil, Y., Kuyumcu, M.E., Neyal, M., Kepekci, Y., "Is increased red cell distribution width (RDW) indicating the inflammation in Alzheimer's disease (AD)?”, Arch Gerontol Geriatr, 56(1), 50-4,2013. 
[28] Albayrak, S., Zengin, K., Tanik, S., Bakirtas, H., Imamoglu, A., Gurdal, M., "Red cell distribution width as a predictor of prostate cancer progression", Asian Pac J Cancer Prev, 15(18),7781-4,2014.

[29] Edwards, T.J., Dickinson, A.J., Natale, S., Gosling, J., McGrath, J.S., “A prospective analysis of the diagnostic yield resulting from the attendance of 4020 patients at a protocoldriven haematuria clinic", BJU Int, 97,301-5,2006.

[30] Siegel, R.L., Miller, K.D., Jemal, A., "Cancer statistics”, CA Cancer J Clin ,68(1),7-30,2018.

[31] Davis, R., Jones, J.S., Barocas, D.A., et al., "Diagnosis, evaluation and follow-up of asymptomatic microhematuria (AMH) in adults: AUA guideline ”, J Urol., 188,2473-2481,2012.

[32] Huang, X.Z., Chen, W.J., Zhang, X., Wu, C.C., Zhang, C.Y., Sun, S.S., Wu, J., “An Elevated Platelet-to- ymphocyte Ratio Predicts Poor Prognosis and Clinicopathological Characteristics in Patients with Colorectal Cancer: A Meta-Analysis”, Dis Markers, 1053125,2017.

[33] Wang, W., Bian, C., Xia, D., He, J.X., Hai, P., Zhao, R., Wang, Y.Y., “Combining Carcinoembryonic Antigen and Platelet to Lymphocyte Ratio to Predict Brain Metastasis of Resected Lung Adenocarcinoma Patients”, Biomed Res Int., 8076384, 2017.

[34] Stone, R.L., Nick, A.M., McNeish, I.A., Balkwill F., Han, H.D., Bottsford-Miller, J., et al.,"Paraneoplastic thrombocytosis in ovarian cancer", $N$ Engl J Med., 16, 366(7),610-8,2012.

[35] Levin, J., Conley, Cl., "Thrombocytosis Associated With Malignant Disease", Arch Intern Med,114:497-500,1964.

[36] Sasaki, K., Kawai, K., Tsuno, N.H., Sunami, E., Kitayama, J., "Impact of preoperative thrombocytosis on the survival of patients with primary colorectal cancer", World J Surg., 36(1)192-200,2012.

[37] Taucher, S., Salat, A., Gnant, M., Kwasny, W., Mlineritsch, B., Menzel, R.C., Schmid, M., Smola ,M.G., Stierer, M., Tausch, C., Galid, A., Steger, G., Jakesz, R., "Impact of pretreatment thrombocytosis on survival in primary breast cancer., Austrian Breast and Colorectal Cancer Study Group", Thromb Haemost, 89(6),1098-106.2003.

[38] Temur, M., Cift, T., Aktas, F.N., "Comparison of Hemogram and Hormone Parameters in Women with Dysfunctional Uterine Bleeding”, Med J SDU / SDÜ Tip Fak Derg ., 25(1),2632,2018 .

[39] Toxqui, L., Pérez-Granados, A.M., Blanco-Rojo, R., Wright, I., Vaquero, M.P., “A simple and feasible questionnaire to estimate manstrual blood loss: relationship with hematological and gynecological parameters in young women”, BMC Womens Health, 14,71-75,2014.

[40] Işık, B., Büyükcam, F., Ekiz, F., Atik, D., Karakılıç, M.E., "Comparison of some of the scoring systems and mean platelet volume in the prediction of mortality in patients admitted to the emergency department with upper gastrointestinal bleeding", Abant Med , 3(3),242-247,2014

[41] Von, D.A., Curtis, B.R., Bougie, D.W. et al., "Vancomycin-induced immune thrombocytopenia", N Engl J Med., 356,904-10, 2007. 
[42] Piel- Julian, M.L., Mahévas, J., Germain, L., Languille, T., Comont, Lapeyre- Mestre, M. Et al, "Risk factors for bleeding, including platelet count threshold, in newly diagnosed immune thrombocytopenia adults", J Thromb Haemost, 16(9),1830-1842,2018.

[43] Bath, P.M., Butterworth, R.J., "Platelet size: measurement, physiology and vascular disease", Blood Coagul Fibrinolysis, 7(2),157-61,1996.

[44] Okur, N., Buyuktiryaki, M., Uras, N., Oncel, M.Y., Ertekin, O., Canpolat, F.E., Oguz, S.S., "Platelet mass index in very preterm infants: can it be used as a parameter for neonatal morbidities?", J Matern Fetal Neonatal Med., 29,3218-3222,2016.

[45] Korkmaz, L., Baştug, O., Ozdemir, A., Korkut, S., Karaca, C., Akin, M.A., Gunes, T., Kurtoglu, S., Ozturk, M.A., "The efficacy of propranolol in retinopathy of prematurity and its correlation with the platelet mass index", Curr Eye Res, 42,88-97,2017.

[46] Demiray, O., Cevik, E., Cuce, F., "Association Between Complete Blood Count Parameters and Urinary Stone Disease”, Iran Red Crescent Med J, 18(7), e24319,2016.

[47] Senel, T., Ates' I., Demir, B.F., Arıkan, M.F., Karaahmetoglu, S., Altiparmak, E., Yilmaz, N., "The diagnostic and prognostic value of platelet indices in gastrointestinal bleeding", Am J Emerg Med, 37(4), 657-663,2019.

[48] Lowe, G.C., Fickowska, R., Ghaithi, R.A., Maclachlan, A., Harrison, P., Lester, W. et al., "Investigation of the contribution of an underlying platelet defect in women with unexplained heavy menstrual bleeding", Platelets, 30(1), 56-65,2019.

[49] Riedl, J., Posch, F., Königsbrügge, O., Lötsch, F., Reitter, E.M., Eigenbauer, E. et al., "Red Cell Distribution Width and Other Red Blood Cell Parameters in Patients with Cancer: Association with Risk of Venous Thromboembolism and Mortality", PLoS One, 9(10),e111440,2014.

[50] Cakal, B., Akoz, A.G., Ustundag, Y., Yalinkilic, M., Ulker, A., Ankarali, H., "Red cell distribution width for assessment of activity of inflammatory bowel disease", Dig Dis Sci, $54,842-847,2009$.

[51] Patel, K.V., Semba, R.D., Ferrucci, L., et al., "Red cell distribution width and mortality in older adults: a meta- analysis”, J Gerontol A Biol Sci Med Sci, 65,258- 265,2010.

[52] Perlstein, T.S., Weuve, J., Pfeffer, M.A., Beckman, J.A., "Red Blood Cell Distribution Width and Mortality Risk in A Community-Based Prospective Cohort: NHANES III: RDW and mortality risk", Arch Intern Med,169, 588-594, 2009. 